\title{
Eyelid and Orbital Infections
}

\author{
Ayub Hakim \\ Department of Ophthalmology, Western Galilee - Nahariya Medical Center, Nahariya, \\ Israel
}

\section{Introduction}

The major infections of the ocular adnexal and orbital tissues are preseptal cellulitis and orbital cellulitis. They occur more frequently in children than in adults. In Schramm's series of 303 cases of orbital cellulitis, $68 \%$ of the patients were younger than 9 years old and only $17 \%$ were older than 15 years old.

Orbital cellulitis is less common, but more serious than preseptal. Both conditions happen more commonly in the winter months when the incidence of paranasal sinus infections is increased. There are specific causes for each of these types of cellulitis, and each may be associated with serious complications, including vision loss, intracranial infection and death. Studies of orbital cellulitis and its complication report mortality in 1- 2\% and vision loss in $3-11 \%$. In contrast, mortality and vision loss are extremely rare in preseptal cellulitis.

\subsection{Definitions}

Preseptal and orbital cellulites are the most common causes of acute orbital inflammation. Preseptal cellulitis is an infection of the soft tissue of the eyelids and periocular region that is localized anterior to the orbital septum outside the bony orbit. Orbital cellulitis ( 3.5 per $100,00)$ is an infection of the soft tissues of the orbit that is localized posterior to the orbital septum and involves the fat and muscles contained within the bony orbit. Both types are normally distinguished clinically by anatomic location.

\subsection{Pathophysiology}

The soft tissues of the eyelids, adnexa and orbit are sterile. Infection usually originates from adjacent non-sterile sites but may also expand hematogenously from distant infected sites when septicemia occurs. Preseptal cellulitis usually originates from skin infection with or without local trauma. It may also originate from structures inside the eyelid that are connected to the surface and become infected such as external and internal hordeolom. Chalazion is an example of internal hordeolom and these are all infected glands with surface connections. Glands with even partial preseptal location such as the lacrimal gland, in which the palpebral lobe is located preseptally, may also cause preseptal cellulitis.

Orbital cellulitis occurs in the following three situations:

- Spreading of an infection from the periorbital structures, usually from the paranasal sinuses, but also from the face, the globe and the lacrimal sac. 
- Direct inoculation of the orbit from surgical trauma.

- Hematogenous spread from distant sites (bacteremia).

In case of local cutaneous infection, preseptal cellulitis can arise from the spread of a contiguous anterior eyelid infection such as a chalazion, local trauma resulting in infection such as insect bite, or a foreign body. The skin and, in some instances, the sinuses and lacremal mucosa, are colonized by various microorganisms. Orbital cellulitis following trauma is the consequence of a direct exposure of the orbital contents to these microorganisms. Open periorbital fractures, as well as closed fractures involving the sinuses or the nasal bone, may be a risk factor for orbital infections.

Orbital cellulitis, in contrast, usually arises from spread of infection from the paranasal sinuses. The ethmoid sinus is the most common source that extends to the orbit in children. In adults, pansinusitis is often accompanied by orbital cellulitis and its spread is believed to be caused through the ethmoid or frontal sinuses. The ethmoid sinus separeated from the orbit medially by the thinnest orbital bone - lamina papyracea. Often, the lamina contains congenital dehiscences through which sinus infections can easily spread into the orbit. This may support the frequency of orbital cellulitis secondary to ethmoiditis. The anterior and posterior ethmoidal foramina may also serve as potential passages for infection.

The orbital roof borders the frontal sinus. It is a diploeic bone and is thicker than the lamina papiracea. Infection may spread more easily through the valveless facial veins. Since the frontal sinus is adjacent to the anterior cranial fossa, it may serve as an intermediary for the spread of infection.

The orbital floor that borders the maxillary antrum also contain congenital dehiscences through which infection from the maxillary sinus can enter and facilitate infection spreading.

The posterior medial wall of the orbit borders the sphenoid sinus. Isolated sphenoiditis is rare. The sphenoid may be involved secondary to ethmoiditis. Sphenoethmoidal sinusitis has distinct clinical characteristics. Marked visual loss with or without ophthalmoplegia usually precedes the findings of proptosis and inflammatory orbital signs. This condition is rare due to the thick bony barrier and firm attachment of periorbita to the posterior orbital wall.

One dehiscence or more is often present in orbital walls, particularly in the thin-walled lamina papyracea and this facilitates the spread of infection to the orbit. Posteriorly, the optic nerve within the optic canal is adjacent to the lateral wall of the sphenoidal sinus. Dehiscence can also be found in the lateral wall of the sphenoidal sinus adjacent to the optic canal. The free valveless venous communication between the orbit and the sinus is another reason predisposing the orbit to the spread of adjacent sinus infection.

However, not all orbital cellulitis infections caused by sinus disease are secondary to acute sinusitis. Orbital fracture involving sinuses may allow spreading of an existing chronic sinus infection. Open fractures may also result in orbital cellulitis due to direct contact with the environment. Foreign bodies, such as a glass, wood or orbital floor implants, can cause orbital cellulitis. Infection can extend to the orbit from the eye, teeth, middle ear, or in neglected cases of preseptal cellulitis, from the eyelids and face.

Uncomplicated eyelid, strabismus, cataract surgery, glaucoma valve and retinal surgery may all expose the orbit to infection. Orbital implants that are imbedded and other foreign bodies, 
such as Molteno valve implant, may carry a risk for infection, especially if they are colonized or exposed. Orbital cellulitis secondary to keratitis may develop after radial keratotomy.

Advanced carries with secondary infection, poor dental work or an infected root or dental cyst can cause orbital cellulitis. Extraction of maxillary premolars, molars or canines exposes the patient to orbital infection. The most common pathway for odontico-orbital infections is through the paranasal sinuses. The apices of maxillary molars and premolars are in close proximity to the floor of the maxillary sinus and are, in fact, in direct contact with the maxillary mucosa. Direct fistula to the antrum may be caused by a floor fracture during dental extraction or maxillary mucosa disruption. Infection spreading from the sinus to the orbit can occur through congenital dehiscences in the medial orbital wall or through communication between the venous plexus of the maxillary mucosa and the ophthalmic veins, thereby causing thrombophlebitis.

Another pathway for the spread of infection is the thin buccal cortical plate of the alveolar processes.

Finally orbital cellulitis can occur secondarily from embolic spread in subacute bacterial endocarditis and from other distant organs.

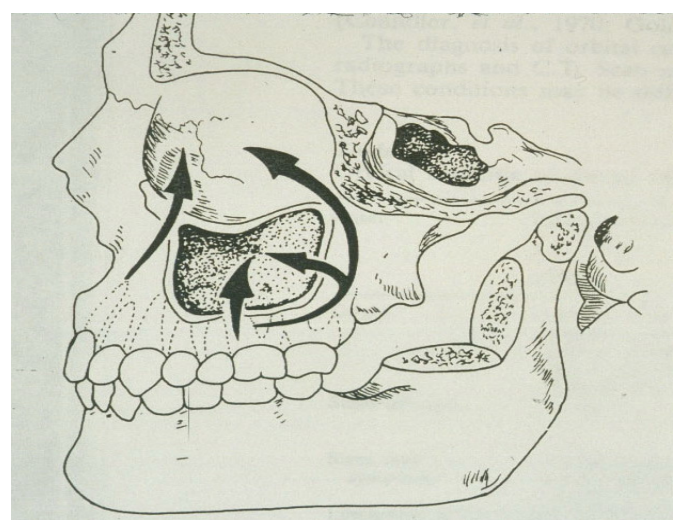

\section{Pathway for odontico-orbital infections}

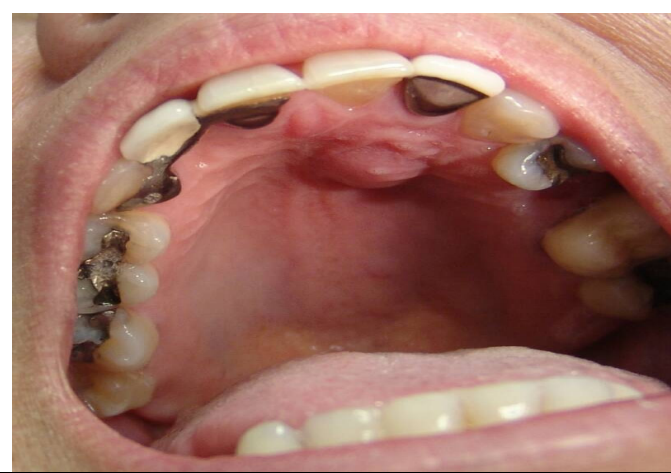

Dental abscess.Predisposing factors:poor dental care, advanced caries, root treatment, following dental extraction. 


\subsection{Classification}

In 1970, chandler described a spectrum of progressive infectious changes in orbital cellulitis.

\section{Chandler's Classification:}

\section{Stage I - Preseptal cellulitis}

Ocasionally, edema may spread secondarily to preseptal cellulitis posterior to the septum without infection. In these cases chemosis may be present, but the extraocular movements and visual acuity remain intact.
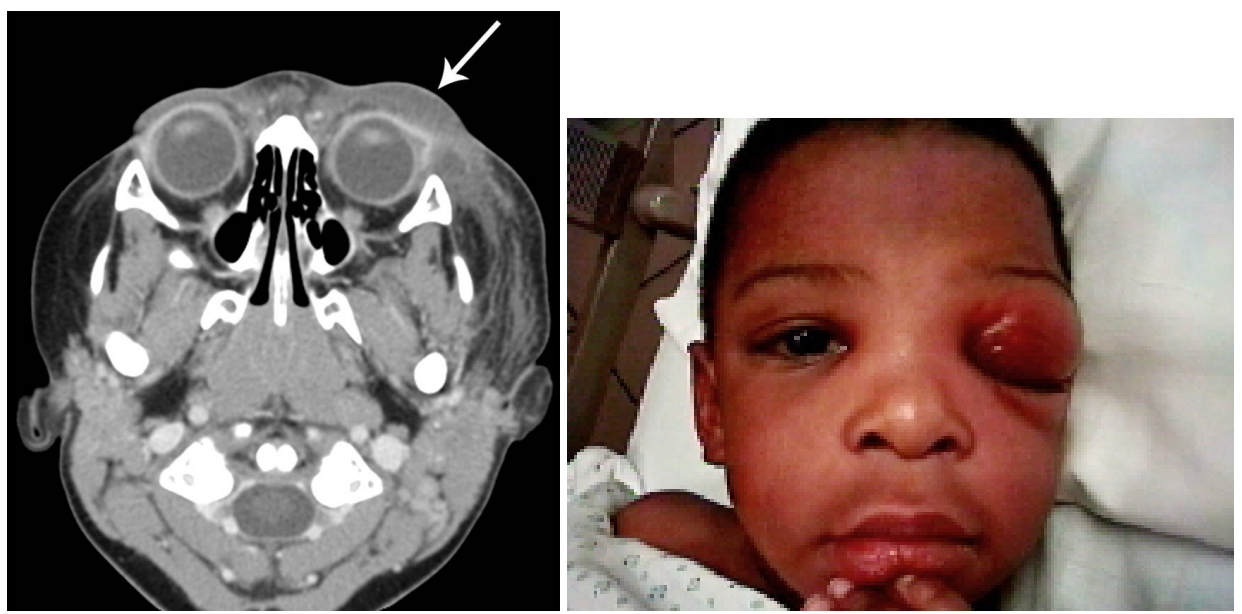

Stage II - Orbital cellulitis

Diffuse edema of orbital contents, with leukocytosis, fever, proptosis and impaired extraocular motility without discrete abscess formation.

Examples are shown in the images below:

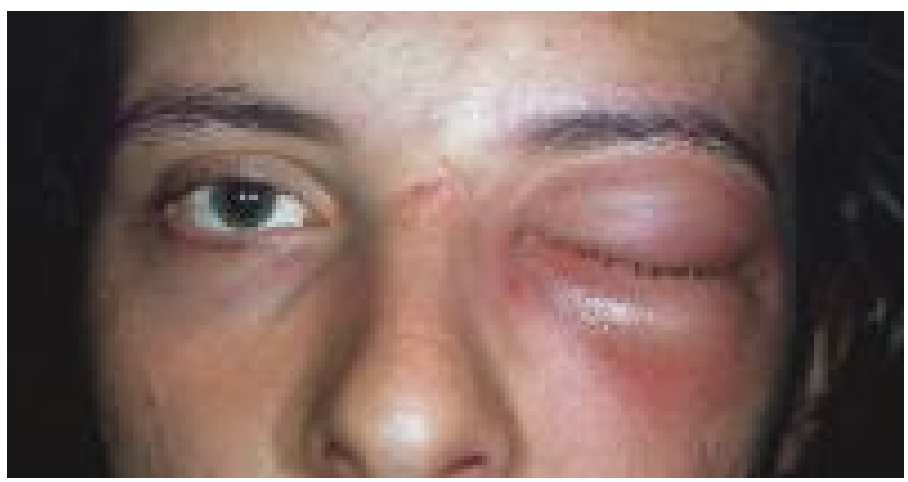

A male with left orbital cellulitis presented with proptosis, ophthalmoplegia, and edema and erythema of the eyelids. The patient also exhibited pain on eye movement, fever, headache, and malaise. 


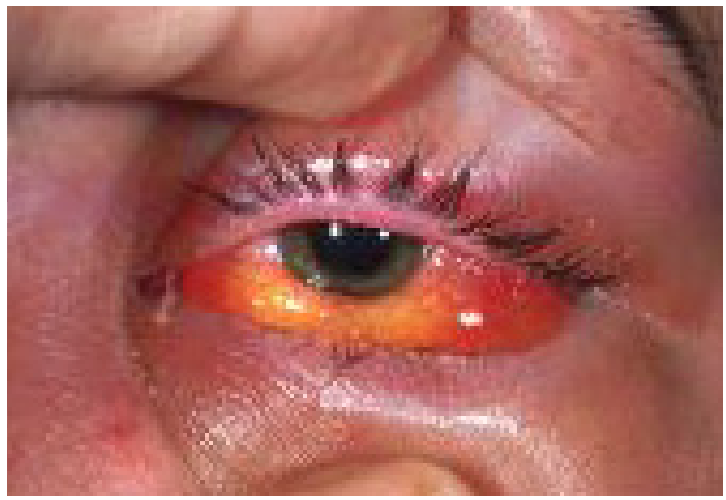

A male with left orbital cellulitis with proptosis, ophthalmoplegia, and edema and erythema of the eyelids. The patient also exhibited chemosis and resistance to retropulsion of the globe.

Stage III - Subperiosteal abscess

The globe is often displaced and limited in the field of gaze of the abscess.

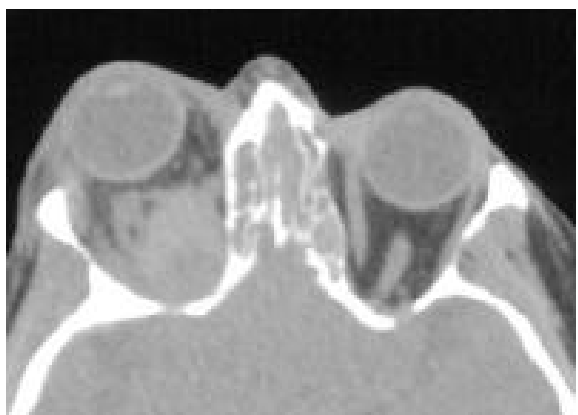

An axial computed tomography scan in a patient with a right orbital infection caused by streptococcus pneumoniae and a right superior orbital subperiosteal abscess that resulted in blindness.

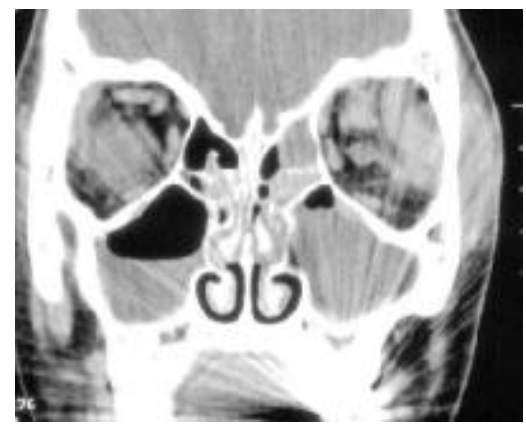

A coronal computed tomography scan of a child with pansinusitis as well as a left orbital and subperiosteal abscess. 


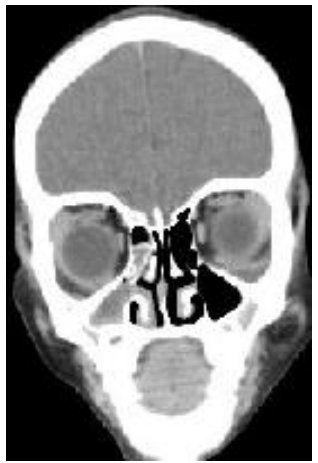

A coronal computed tomography scan in a patient with sickle cell disease. In this image, the patient has a left subperiosteal bleeding that mimiced the appearance of an infectious subperiosteal abscess.

Stage IV - Intraorbital abscess, purulent collection:

These patients have severe proptosis, chemosis, ophthalmoplegia and often visual loss.

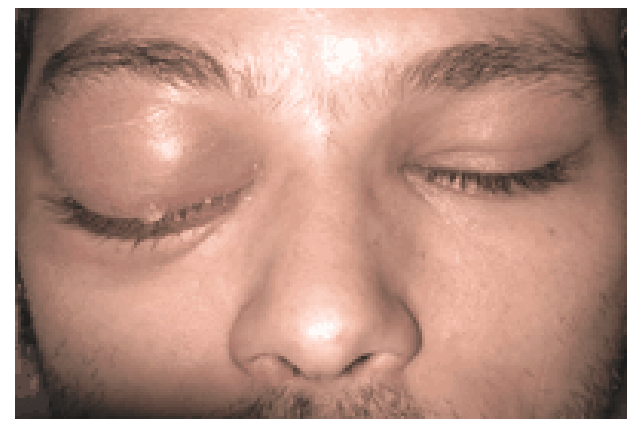

Frontal view of the patient with a right orbital abscess showing periorbital redness, swelling and proptosis.

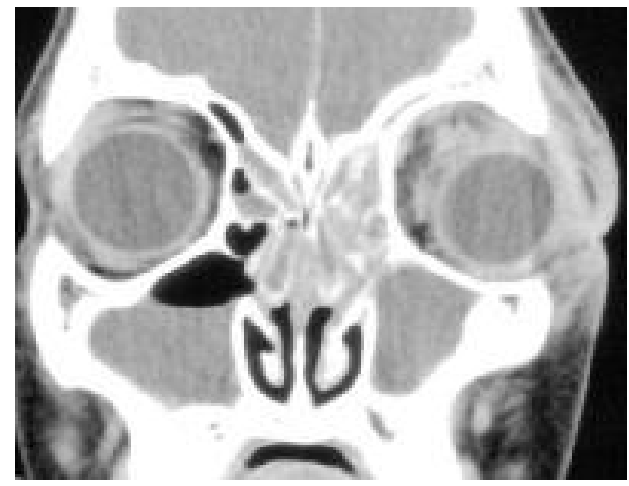

Coronal computed tomography scan in a pediatric patient with pansinusitis sinusitis and left orbital abscess. 


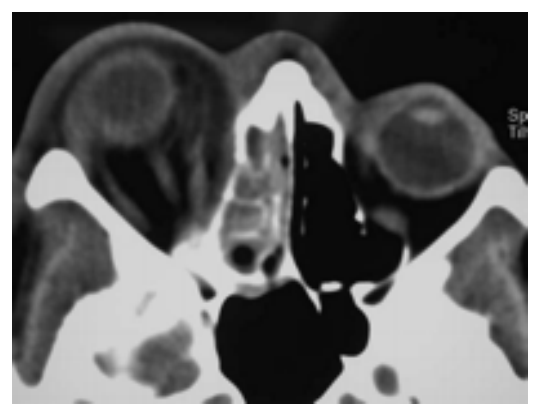

Axial computerized tomography scan shows a right classic proptosis associated with an abscess of the orbit, as well as displacement of the medial orbital tissues and tenting of the posterior.

Stage V - Cavernous sinus thrombosis (septic abscess)

In these instances, the orbital signs evolve in the fellow eye (bilateral) and other central nervous system signs supervene.
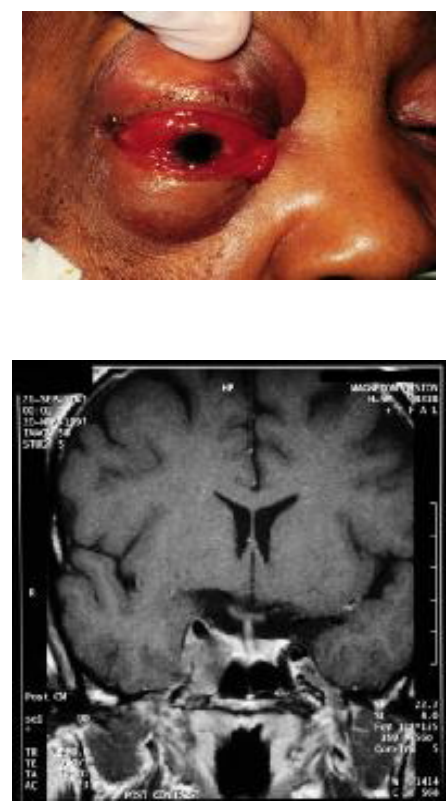

A T1 weighted coronal MRI demonstrating asymmetry between the caverenous sinuses with obliteration of the right cavernous sinus.

\section{Preseptal cellulitis}

Preseptal cellulitis is more common than orbital cellulitis. It can present with swelling and erythema of tissues surrounding the orbit, with or without fever. Preseptal cellulitis most commonly occurs from a contiguous infection of the soft tissues of the face and eyelids 
secondary to local trauma, foreign bodies or insect or animal bites. It is rare for untreated preseptal cellulitis to progress to orbital cellulitis by local extension. Defining the exact location of inflammation is essential for proper diagnosis and treatment.

\subsection{Symptoms and signs}

Patients with preseptal cellulitis often have a short history (days) of painless swelling of the eyelids. A history of early upper respiratory tract infection, trauma, insect or animal bite, conjunctivitis, or chalazion may be disclosed. Fever is an inconstant feature. The eyelid characteristically is erythematous, edematous, tender and warm. Vision and pupillary response are always unaffected and proptosis, globe displacement and limitation in ocular motility are never present. Concurrent preseptal cellulitis was discovered in the presence of many systemic diseases including, varicella, asthma, nasal polyposis and neutropenia. Preseptal cellulitis is more common among children than in adults.

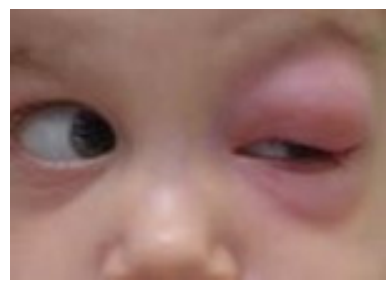

Preseptal cellulitis is more common in children than in adults.

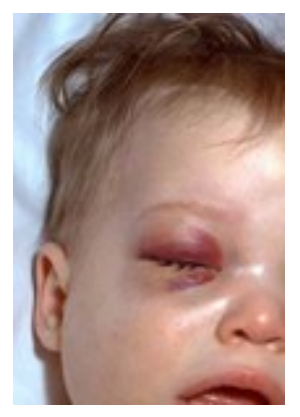

swelling and erythema of soft tissues surrounding the orbit.

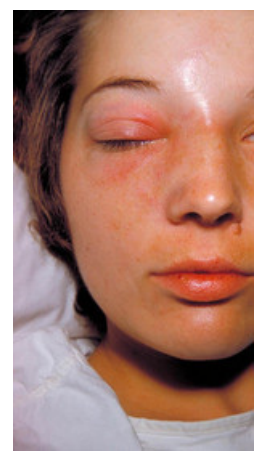

Eyelid swelling, erythema, local warmth, tenderness.no proptosis, limited ocular motility or optic nerve involvement.

\subsection{Microbiology}

The most common inciting microorganisms include Streptococcus pneumoniae, Staphylococcus aureus, other Streptococcus species and anaerobes. Haemophilus infuenzae type B was the most common cause in children under four years old. However, routine vaccination with conjugate Haemophilus influenzae vaccines since 1985 has dramatically decreased this infection in young children. Less commonly implicated microorganisms include Acinetobacter spp., Nocardia brasiliensis, Bacillus anthracis, Pseudomonas aeruginosa, Neisseria gonorrhoea, Proteus spp., Pasteurella multocida, Mycobacterium tuberculosis and Trichophyton spp.

\subsection{Differential diagnosis}

Conditions that might masquerade as preseptal cellulitis include allergic edema (anaphylactoid reaction) of the eyelids, severe blepharitis with scruffs (seborrheic), 
collarets(staphylococcal), sleeves(demodex) with or without erythema but no local warmth. The meibomianitis is characterised with eyelid swelling, pouting of meibomian gland orisices and discharge from orifices but no local warmth.

In addition dacryoadenitis, blunt trauma, thyroid eye disease, leukemic infiltrates, blepharochalasis syndrome and autoimmune inflammatory disorder such as lupus. Other disorders of less resemblance include orbital tumors/pseudotumours (, orbital vasculitis, necrotising fascitis and others.

\subsection{Management}

Treatment regimens cover the most likely organisms to cause infection in this setting and according to case series. Outpatient treatment should include broad-spectrum oral antibiotics and close observation. The author came to a conclusion that most cases of preseptal cellulitis can be safely managed as outpatients with oral antibiotics and follow-up until improvement is documented. If the condition does not improve or deteriorates 48 hours or more after oral antibiotic treatment, the patients should be admitted for intravenous antibiotic treatment and close observation. The average time of hospitalization is four days.

The appropriate antibiotics in adults include Amoxicillin-clavulinate (Augmentin) $875 \mathrm{mg}$ every $12 \mathrm{~h}$, and in children $90 \mathrm{mg} / \mathrm{kg} /$ day amoxicillin and $6.4 \mathrm{mg} / \mathrm{Kg} /$ day of clavulanate divided to two doses. Another option includes Cefpodoxime (Vantin ) $200 \mathrm{mg}$ every $12 \mathrm{~h}$ in adults, and $10 \mathrm{mg} / \mathrm{kg} / \mathrm{d}$ divided every $12 \mathrm{~h}$ in children with maximum daily dose of 400 mg. Cefdinir ( Omnicef ) $600 \mathrm{mg}$ daily in adults, and $14 \mathrm{mg} / \mathrm{kg} / \mathrm{d}$ divided every $12 \mathrm{~h}$ in children with maximum daily dose $600 \mathrm{mg}$ is another option.

Pediatric patients under 1 year of age and all more severe cases require the same approach as patients with orbital cellulitis, namely, intravenous broad-spectrum antibiotics and hospital observation .Blood cultures should be obtained if the systemic fever increases. The recommended duration of antimicrobial therapy is for 7-10 days. Occasionally, patients will continue to have local signs of cellulitis at end of treatment. Oral antibiotic therapy is recommended to be continued in these patients until resolution of the erythema. Children with preseptal cellulitis, no orbital involvement, and who do not appear toxic can be treated with intramuscular or oral antibiotics on a daily basis as outpatients. Preseptal cellulitis in adults can be managed on outpatient basis with oral antibiotics with frequent monitoring for progression.

\section{Orbital cellulitis}

Orbital cellulitis occurs in three settings:

i. Extension of infection from periorbital structures, such as the face, lacrimal sac and globe, but particularly from the paranasal sinuses. Acute sinusitis is complicated by orbital cellulitis in 1-3\% of cases and the coexisting sinusitis is present in $73-94 \%$ of patients with orbital cellulitis. Ethmoid sinusitis and pansinusitis are most likely to progress to orbital cellulitis. The first ocular sign of sinusitis may be preseptal inflammation only. This can then quickly progress to the classic clinical picture of orbital cellulitis. Other causes include - orbital trauma, with fracture or a foreign body, dacryocystitis, and infection of teeth, middle ear or face. 
ii. Direct inoculation from accidental trauma or from surgery. Orbital cellulitis is uncommon complication of ophthalmic surgery, being reported after strabismus surgery, blepharoplasty, radial keratotomy, retinal surgery and following peribulbar anesthesia. A special case is fungal orbital cellulitis, a relatively rare condition occurring in two principal forms - 1. Subacute infection due to genera of Zygomacetes (mucormycosis). 2. A more chronic orbital infection caused by species of Aspergillus. The distinction between these two may be difficult on clinical observation alone.

iii. Hematogenous spread (endogenous from bacteremia). The microorganisms responsible for most cases are aerobic non-spore forming bacteria.

\subsection{Symptoms and signs}

Orbital cellulitis as preseptal cellulitis can present with swelling and erythema. The cardinal signs and symptoms are proptosis, ophthalmoplegia and globe displacement. Pain on eye movement, vision loss (indicates orbital apex involvement), diplopia, conjunctival chemosis and elevated intraocular pressure are common but variable accompanying signs.

\subsection{Microbiology}

S. aureus and Streptococci are the most commonly identified organisms in culture-positive orbital cellulitis. Less common causes are $H$. influenza and non-spore forming anaerobes. However, many other common and rare bacterial pathogens include Eikenella corrodens, Aeromonas hydrophilia, P. aeroginosa, fungal and mycobacterial pathogens, including Scedosporium apospermum, M. tuberculosis and Mycobacterium avium complex. The prognosis of aspergillosis is poor. More than $80 \%$ of reported patients have died from this causative.

\subsection{Differential diagnosis}

Conditions that may mimic orbital cellulitis include:

- Anaphylactoid reaction can be characterised with eyelid swelling and erythema but no local warmthand no proptosis, limited ocular motility or optic nerve involvement.

- Cavernous sinus syndrome that is characterised by proptosis, complete ophthalmoplegia, optic nerve involvement, V2 involvement, evolve to bilateral condition and usually in debilitated patients (diabetics, drug abusers, HIV).

- The orbital apex syndrome is characterised with complete external ophthalmoplegia, optic nerve and V1 involvement with/without proptosis.

- Superior orbital fissure syndrome is a condition that is characterised with complete external ophlmoplegia, V1 involvement with or without proptosis.

- The orbital compartment syndrome and the orbital tumors can present with proptosis, limited ocular motility, optic nerve involvement and increased intraocular pressure but no local warmth.

\subsection{Diagnosis}

There have been no controlled trials examining the utility of radiologic studies (e.g. computed tomography scanning, orbital ultrasound, or magnetic resonance imaging) in the diagnosis of orbital cellulitis or in distinguishing preseptal from orbital cellulitis. 


\section{Computed Tomography scanning (CT)}

CT can confirm extension of inflammation into the orbit, detect coexisting sinus disease, and identify an orbital or subperiosteal abscess. Whether every patient with suspected orbital cellulitis needs a CT scan is controversial. Some experts suggest that a CT scan be performed only in those patients who deteriorate or fail to respond to 48 hours of IV antibiotics, as the majority of patients with orbital cellulitis do well with conservative medical management. It is suggested that patients with suspected orbital cellulitis - those with proptosis, globe displacement, limitation of eye movements, double vision, vision loss, and those patients in whom the physician cannot accurately assess vision - usually patients less than one year of age, at presentation have a baseline CT scan.

\section{Orbital Ultrasunography(US)}

US provides higher-resolution details of orbital contents and is useful when sequential follow-up of an abscess or drained abscess is required. However, orbital sonography is not widely available and is dependent on the expertise of the sonographer.

\section{Magnetic Resonance Imaging (MRI)}

MRI is superior to CT in the resolution of soft tissue disease. However, it is not usually performed because of the need for sedation in pediatric patients and because MRI is rarely immediately available.

\section{Microbiologic studies}

The causative microorganism in orbital cellulitis may be difficult to identify due to normal flora contaminants, mixed infection, and prior antibiotic therapy. Cultures for aerobic and anaerobic organisms may be obtained from blood, sinus aspirates, and abscess. Because blood cultures are usually negative, some clinicians obtain cultures of eye secretions or pharyngeal culture. However, these cultures are likely to be contaminated with normal oropharyngeal flora and should not guide the choice of antibiotic therapy. Microbiologic data limited to microorganisms recovered by surgical drainage from orbital abscesses or involved sinuses and/or positive blood culture are the most reliable information. It is recommended that in patients with suspected orbital cellulitis, blood cultures should be obtained before the initiation of antibiotic treatment. If surgery is performed, culture of abscess material or sinus contents should be sent for aerobic, anaerobic and fungal cultures.

\subsection{Complications}

The complications of bacterial orbital cellulitis may be orbital or intracranial. Orbital complications of orbital cellulitis include subperiosteal or orbital abscess formation in 7-9\%, permanent globe displacement, limited ocular motility that may cause diplopia, and vision loss in $1 \%$. Orbital abscess may be clinically indistinguishable from orbital cellulitis. Proptosis and globe displacement tends to be more severe with orbital abscess than in orbital cellulitis, and patients are more likely to be systemically ill. The diagnosis of orbital abscess is confirmed by imaging or at surgery. The identification of an orbital abscess on the baseline CT scan is important since these patients almost always require surgery. Intracranial complications, which are encountered in $4 \%$ of orbital cellulitis secondary to sinusitis include meningitis in $2 \%$, cavernous sinus thrombosis in $1 \%$, intracranial abscess 
formation, epidural or subdural abscess or parenchymal brain abscess in $1 \%$, and carotid artery occlusion. Intracranial involvement may be heralded by ophthalmoplegia, changes in mental status, contralateral cranial nerve palsy, or bilateral orbital cellulitis. Cavernous sinus thrombosis has become relatively rare in developed countries because of prompt and adequate treatment of most cases of acute sinusitis, but it still poses a major threat. The mortality rate of cavernous sinus thrombosis may exceed $50 \%$.

\section{Permanent vision loss may occur because of:}

1. Corneal ulcer and perforation secondary to exposure or neurotrophic keratitis.

2. Destruction of intraocular tissues following neovascular or inflammatory glaucoma, endophthalmitis, septic uveitis or retinitis and exudative retinal detachment.

3. Various other mechanisms affecting the globe or posterior orbit, such as secondary glaucoma due to elevated orbital pressure, infectious optic neuritis or inflammatory optic neuritis, pressure effects the optic nerve, thrombophlebitis of ocular veins and central retinal artery occlusion.

Blindness can result from elevated intraorbital pressure causing optic neuropathy or extension of the infection to the optic nerve from the sphenoid sinus.

\subsection{Management}

Prompt administration of appropriate antibiotics is the key for successful treatment of orbital cellulitis. After appropriate workup, all periorbital and orbital infections should be treated with broad-spectrum antimicrobial agents. There have been no controlled trials examining the required duration of antimicrobial therapy in orbital cellulitis. Treatment regimens are based upon coverage of the most likely organisms to cause infection in this setting and treatment of case series. The initial empiric antibiotic treatment should consist of parenteral broad-spectrum therapy. Infection due to methicillin-resistant $S$. aureus is best treated with vancomycin, clindamycin and cefotaxime.

Fungal orbital cellulitis occurs and is primarily due to mucor and aspergillums species. It requires antifungals, such as amphotericin. Corticosteroids may be helpful in bacterial infections, but they should not be started before surgery and until the patient has been on appropriate antibiotics for 2-3 days to ascertain eradication of the microbial agents.

If secondary glaucoma develops, ocular anti-hypertensive agents should be initiated promptly. Prompt diagnosis and therapy are important since delayed intervention can result in sustained vision loss.

\subsubsection{Antibiotic treatment}

Due to increasing incidence of Methicillin-resistant $S$. Aureus, empiric therapy with Vancomycin (Vancocin) (15 mg/kg IV every 12 hours in adults, 10 to $15 \mathrm{mg} / \mathrm{kg}$ IV every 6 hours in children, maximum daily dose of $4 \mathrm{gr}$ ) is recommended. If susceptibility testing reveals Methicillin-sensitive $S$. aureus, Vancomycin should be replaced with Nafcilin (Unipen), or Oxacillin ( Bactocill ) - (both agents are dosed at 2gr IV every 4 hours in adults, and $200 \mathrm{mg} / \mathrm{kg}$ per day IV in 4-6 divided doses in children, maximum daily dose of 12gr) since these agents have better CNS penetration than vancomycin. 
One of the following should be added:

1. Ampicillin-sulbactam ( Unasyn ) 3gr IV every 6 hours in adults, $300 \mathrm{mg} / \mathrm{kg}$ per day in 4 divided doses in children, maximum daily dose of $12 \mathrm{gr}$.

2. Ticarcillin-clavulanate (Ticar), which covers most of the Gram-negative bacteria as well as Gram-positive organisms, including atypical $H$. influenza, and has also excellent anaerobic coverage. The dosage is 3.1gr IV every 4 hours in adults, $200-300 \mathrm{mg}$ of ticarcillin component per $\mathrm{kg}$ per day in 4-6 divided doses in children of less than $60 \mathrm{~kg}$. The maximum daily dose of ticarcillin component is $18 \mathrm{gr}$.

3. Piperacillin-Tazobactam $4.5 \mathrm{gr}$ IV every 6 hours in adults, $240 \mathrm{mg} / \mathrm{kg}$ per day in 3 divided doses in children, with a maximum daily dose of $16 \mathrm{gr}$ of piperacillin component.

4. Ceftriaxone (Rocephin ) is effective agpenicillinase-producing S. aureus, most Grampositive organisms, and most Gram-negative organisms except for Pseudomonas. Ceftriaxone also crosses the blood-brain barrier; therefore, it is an excellent choice if there is a suspicion of concurrent intracranial infection. 2gr IV every 12 hours in adults, $80-100 \mathrm{mg} / \mathrm{kg}$ per day in 2 divided doses in children, maximum dose of $4 \mathrm{gr}$ daily may be given.

5. Cefotaxime (Claforan), a third-generation cephalosporin that covers most of the common sinus pathogens with the exception of Clostridium difficile, may be given $2 \mathrm{gr}$ IV every 4 hours in adults, $150-200 \mathrm{mg} / \mathrm{kg}$ per day in 3-4 equally divided doses in children, with a maximum daily dose of $12 \mathrm{gr}$.

Patients allergic to penicillin and/or cephalosporins may be treated with a combination of vancomycin and a flouroquinolon. For patients over 17 years of age, ciprofloxacin $500 \mathrm{mg}$ twice a day or levofloxacin $500 \mathrm{mg}$ daily may be prescribed. Flouroquinilones are not recommended for use in pediatric patients as first-line therapy for any infection because of the musculoskeletal side effects - The mildest side effects include muscle pain, called fibromyalgia. A more serious side effect, though also less common, is tendon damage. Fluoroquinolones can, in high doses, cause tendon damage, which can ultimately lead to rupture of the Achilles tendon (in addition gastrointestinal effects predominating (nausea, vomiting, diarrhea, or abdominal pain in $1.0 \%-5.0 \%$ of thepatients), followed byeffects onthecentral nervous system (dizziness, headache, and/or insomnia in $0.1 \%-0.3 \%$ of the patients) and skin $(0.5 \%-2.2 \%$ of the patients). Elevation in levels of hepatic enzymes occurred in $1.8 \%-2.5 \%$ of thepatients, azotemia in $0.2 \%-1.3 \%$, and eosinophilia in $0.2 \%-$ $2.0 \%$. Initial antibiotic therapy should be administered IV under hospitalization. Generally switching to oral therapy is done after the patient is afebrile and skin findings have begun to resolve, which usually take 3-5 days.

The duration of treatment depends on the response. Patients should be treated with parenteral antibiotics until they show clear evidence of clinical improvement as manifested by decrease in orbital congestive signs such as proptosis, gaze limitation, cellulitis and edema. Intravenous therapy should continue for a minimum of 3 days. Then oral antibiotic therapy may be instituted for a total course of 10 days to 3 weeks, depending on the severity of infection. Associated bacteremia, however, should be treated with 7-10 days of IV therapy.

As aforesaid, the oral regimen should be tailored based upon the results of the cultures. If the results are not available, reasonable empiric oral antibiotic choices include 1 . amoxicillin 
- clavulinate - $875 \mathrm{mg}$ twice daily for adults or children over $40 \mathrm{~kg}$, and $45 \mathrm{mg} / \mathrm{kg} /$ day divided every 12 hours for children over 3 moths and under $40 \mathrm{~kg}$ or 2. fluoroquinolone (levofloxacin $750 \mathrm{mg}$ once daily in adults). Linezolid (ZYVOX) - (600 mg twice daily in adults and children over 12 years of age, $10 \mathrm{mg} / \mathrm{kg}$ three times daily for children under 11 years) should be added if MRSA is suspected.

Careful follow-up is indicated in all patients who present with orbital cellulitis. This should include twice-daily examinations with attention to visual acuity, confrontation visual fields, exophthalmometry, motility and pupillary examination.

\subsubsection{Antifungals}

(Amphotericin B- Ambisome) $1 \mathrm{mg} / \mathrm{kg}$ IV q24h or Voriconazole (VFEND, Pfizer ) $6 \mathrm{mg} / \mathrm{kg}$ IV q12h for 2 doses, then $4 \mathrm{mg} / \mathrm{kg}$ IV q12h or Voriconazole 200-300 mg PO q12h

Antifungal is the treatment of choice for fungal orbital cellulitis. It is administered IV and may be appropriately administered before laboratory confirmation of fungal infection in cases of severe infection and debilitated patients (diabetes mellitus, drug abusers, human immunodeficiency disease, metastatic cancer, prolonged administration of antibiotics and/ or corticosteroids).

\subsubsection{Surgery}

The timing for surgical intervention is critical. In cases of orbital cellulitis without abscess formation, in which visual acuity is 20/60 (Snellen notation), 6/15 (metric equivalent) or less, or declines with appropriate medical management, orbital exploration should be emergent. In cases in which the acuity is better than 20/60, the patient should be followed, expectantly, and frequently while more conservative management is initiated.

Orbital surgery is indicated if the patient:

1. Fails to respond

2. Deteriorates clinically despite treatment

3. Has worsening visual acuity or develops afferent pupillary defect

4. Develops an abscess, except selected pediatric cases with medial subperiosteal abscess, which may be successfully treated medically.

In patients older than 14 years of age, the author favours the latter approach because the risks of surgery are negligible compared with the visual and life-threatening risks of no intervention. In patients 9 years of age or younger, $25 \%$ of the subperiosteal abscesses are likely to resolve with antibiotic therapy alone. Several indications have been suggested for drainage of subperiosteal abscesses. These include age of 9 years or older, large abscess, frontal sinusitis, non-medial abscesschronic sinusitis, dental infection, optic nerve involvement, suspicion of anaerobic infection and recurrence after drainage. All other cases may be managed conservatively by intravenous antibiotics.

\section{References}

Abbott RL, Shekter WB: Necrotizing erysipelas of the eyelids. Ann Ophthalmol 11:381, 1979 
Abou-Rayyah Y, Rose GE, Konrad H, et al. Clinical, radiological and pathological examination of periocular dermoid cyst:evidence of inflammation from an early age. Eye (Lond) 2002;16:507.

Adams WG, Deaver KA, Cochi SL, et al: Decline of childhood Haemophilus influenzae type b (Hib) disease in the Hib vaccine era. JAMA 269:221, 1993

Agarwal M, Biswas J, S K, Shanmugam MP. Retinoblastoma presenting as orbital cellulitis: report of four cases with a review of the literature. Orbit 2004;23:93.

Ailal F,Bousfiha A, Jouhad Z, et al. (Orbital cellulitis in children: a retrospective study of 33). Med trop (Mars) 2004; 64:359.

Allan BP,Egbert MA, Myall RW. Orbital abscess of odontologic origin. Case report and review of the literature. Int J Oral Maxillofac surg 1991;20:268.

Allen MV, Cohen KL, Grimson BS. Orbital cellulitis secondary to dacryocystitis following blepharoplasty. Ann Ophthalmol 1985; 17:498.

Ambati BK, Ambati J, Azar N, Stratton L, Schmidt EV: Periorbital and orbital cellulitis before and after the advent of haemophilus influenzae type B vaccination. Ophthalmology 107:1450, 2000

Antoine GA, Grundfast KM: Periorbital cellulitis. Int J Pediatr Otorhinolaryngol 13:273, 1987

Arjmand EM, Lusk RP, Muntz HR. Pediatric sinusitis and subperiosteal orbital abscess formation:diagnosis and treatment. Otolaryngol Head Neck Surg 1993;109:886.

Ataullah S, Sloan B. Acute dacryocystitis presenting as an orbital absvess. Clin Experiment ophthalmol 2002;30:44.

Bach MC, Knowland M, Schuyler WBJ: Acute orbital myositis mimicking orbital cellulitis. Ann Intern Med 109:243, 1988

Barkin RM, Todd JK: Periorbital cellulitis in children. Pediatrics 62:390, 1978

Barman Balfour JA, Lamb HM: Moxifloxacin, a review of its potential in the management of community-acquired respiratory tract infections. Drugs 59:115, 2000

Barone SR, Aiuto LT. Periorbital and orbital cellulitis in the Haemophilus influenzae vaccine era. J Pediatr Ophthalmol Strabismus 1997; 34:293.

Batson OV: Relationship of the eye to the paranasal sinuses. Arch Ophthalmol 16:322, 1936

Bergin DJ, Wright JE: Orbital cellulitis. Br J Ophthalmol 70:174, 1986

Botting AM, McIntosh D, Mahadevan M. Paediatric pre- and post-septal peri-orbital infections are different diseases. A retrospective review of 262 cases. Int J Pediatr Otorhinolaryngol 2008; 72:377.

Brannan PA, Kersten RC, Hudak DT, et al. Primary Nocardia brasiliensis of the eyelid. Am J Ophthalmol 2004; 138:498.

Brenner DJ, Elliston CD, Hall EJ, Berdon WE: Estimated risks of radiation-induced fatal cancer from pediatric CT. AJR 176:289, 2001

Brook I, Frazier EH. Microbiology of subperiosteal orbital abscess and associated maxillary sinusitis. Laryngoscope 1996; 106:1010.

Bullock JD, Fleishman JA: The spread of odontogentic infections to the orbit: diagnosis and management. J Oral Maxillofac Surg 43:749, 1985

Caça I, Cakmak SS, Unlü K, et al. Cutaneous anthrax on eyelids. Jpn J Ophthalmol 2004; 48:268.

Carter BL, Bankoff MS, Fisk JD: Computed tomographic detection of sinusitis responsible for intracranial and extracranial infections. Radiology 147:739, 1983 
Casteel I, DeBleecker C, Demaerel P, et al: Orbital myositis following an upper respiratory tract infection: contribution of high resolution CT and MRI. J Belg Radiol 74:45, 991

Catalano RA, Smoot CN: Subperiosteal orbital masses in children with orbital cellulitis: time for a reevaluation? J Pediatr Ophthalmol Strabismus Surg 27:141, 1990

Chalumeau M, Tonnelier S, d'Athis P, et al: Fluoroquinolone safety in pediatric patients: a prospective, multicenter, comparative cohort study in France. Pediatrics 111:714, 2003

Chandler JR, Langenbrunner DJ, Stevens ER: The pathogenesis of orbital complications in acute sinusitis. Laryngoscope 80:1414, 1970

Chaudhry IA, Shamsi FA, Elzaridi E, et al. Inpatient preseptal cellulitis: experience from a tertiary eye care centre. Br J Ophthalmol 2008; 92:1337.

Chaudhry IA, Shamsi FA, Elzaridi E, et al. Outcome of treated orbital cellulitis in a tertiary eye care center in the middle East. Ophthalmology 2007; 114:345.

Chou SY, Tsai CC, Kau SC, et al. Aeromonas hydrophila orbital cellulitis in a patient with myelodysplastic syndrome. J Chin Med Assoc 2004; 67:51.

Claudia F E Kirsch, MD, Roger Turbin, MD, Devang Gor, MD, Barton F Branstetter IV, MD, Bernard D Coombs, MB, ChB, PhD, C Douglas Phillips, MD, Robert M Krasny, MD, James G Smirniotopoulos, MD (Orbital Infection Imaging ) - Updated: May 27, 2011.

David G Hunter , MD, PhD, Michele Trucksis, Phd, MD, Stephen B Calderwood, MD, Morven S Edwards, MD, Jonathan Trobe, MD, Anna R Thorner, MD, Uptodate review version 19.2:2011 May.

Donahue Sp, Khoury JM, Kowalski RP: Common ocular infections. Drugs 52:526, 1996

Duane's Ophthalmology, William, M.D. Tasman, Edward A., M. Jaeger, Publisher: Lippincott Williams \& Wilkins, ISBN: 0781725879 DDC: 617 Edition: Hardcover; 2000-09

Dudin A, Othman A. Acute periorbital swelling: evaluation of management protocol. Pediatr Emerg Care 1996; 12:16.

Eustis HS, Mafee MF, Walton C, Mondonca J: MR imaging and Ct of orbital infections and complications in acute rhinosinusitis. Radiol Clin North Am 36:1165, 1998

Filips RF, Liudahl JJ. Asymptomatic posterior orbital cellulitis resulting from ethmoid/maxillary sinusitis. J Am Optom Assoc 1997; 68:55.

Forstot SL, Ellis PP: Nontraumatic rupture of the globe secondary to orbital cellulitis. Am J Ophthalmol 88:262

Frederick J, Braude AI: Anaerobic infection of the paranasal sinuses. N Engl J Med 290:135, 1974

Galetta SL, Wulc AE, Goldberg HI, et al: Rhinocerebral mucormycosis: management and survival after carotid occlusion. Ann Neurol 28:103, 1990.

Gamble RE: Acute inflammations of the orbit in children. Arch Ophthalmol 10:483, 1933

Ganesh A, Venugopalan P. Preseptal orbital cellulitis following oral trauma. J Pediatr Ophthalmol Strabismus 2000; 37:315.

Gans H, Sekula J, Wlodyka J: Treatment of acute orbital complications. Arch Ophthalmol 100:329, 1974

Garcia GH, Harris GJ, Criteria for nonsurgical management of subperiosteal abscess of the orbit: analysis of outcomes 1988-1998. Ophthalmology 2000;107:1454-6. 
Gellady AM, Shulman ST, Ayoub EM: Periorbital and orbital cellulitis in children. Pediatrics 61:272, 1978

Givner LB. Periorbital versus orbital cellulitis. Pediatr Infect Dis J 2002; 21:1157.

Gold SC, Arrigg PG, Hedges TR: Computerized tomography in the management of acute orbital cellulitis. Ophthalmic Surg 18:753, 1987

Goldberg F, Berne AS, Oski FA: Differentiation of orbital cellulitis from preseptal cellulitis by computed tomography. Pediatrics 62:1000, 1978

Goldfarb MS, Hoffman DS, Rosenberg S: Orbital cellulitis and orbital fractures. Ann Ophthalmol 19:97, 1987

Goodwin WJ, Weinshall M, Chandler JR: The role of high resolution computerized tomography and standardized ultrasound in the evaluation of orbital cellulitis. Laryngoscope 92:728, 1982

Greenberg MF, Pollard ZF. Medical treatment of pediatric subperiosteal orbital abscess secondary to sinusitis. J AAPOS 1998; 2:351.

Grossniklaus HE, Wojno TH: Leukemic infiltrate appearing as periorbital cellulitis. Arch Ophthalmol 108:484, 1990

Hajek M:Complications involving the orbit and visual organ. In Pathology and Treatment of Inflammatory Disease of the Nasal Accessory Sinuses. vol 2, 1926578-606

Handler LC, Davey IC, Hill JC, Lauryssen C: The acute orbit: differentiation of orbital cellulitis from periosteal abscess by computerized tomography. Neuroradiology 33:15, 1991

Harr DL, Quencer RM, Abrams GW: Computed tomography and ultrasound in the evaluation of orbital infection and pseudotumor. Radiology 142:395, 1982

Harris GJ. Age as a factor in the bacteriology and response to treatment of subperiosteal abscess of the orbit. Trans Am Ophthalmol Soc 1993; 91:441.

Harris GJ. Subperiosteal abscess of the orbit. Age as a factor in the bacteriology and response to treatment. Ophthalmology 1994; 101:585.

Harris GJ: Subperiosteal abscess of the orbit. Arch Ophthalmol 101:751, 1983

Hawkins DB, Clark RW: Orbital involvement in acute sinusitis. Clin Pediatr 16:464, 1977

Haynes R, Cramblett H: Acute ethmoiditis. Am J Dis Child 114:261, 1967

Hegde V, Smith G, Choi J, Pagliarini S. A case of gonococcal kerato-conjunctivitis mimicking orbital cellulitis. Acta Ophthalmol Scand 2005; 83:511.

Hemady R, Zimmerman A, Katzen BW, Karesh JW. Orbital cellulitis caused by Eikenella corrodens. Am J Ophthalmol 1992; 114:584.

Hirsch M, Lifschitz T: Computerized tomography in the diagnosis and treatment of orbital cellulitis. Pediatr Radiol 18:302, 1988

Hofbauer JD, Gordon LK, Palmer J. Acute orbital cellulitis after peribulbar injection. Am J Ophthalmol 1994; 118:391.

Hornblass A, Herschorn BJ, Stern K, Grimes C: Orbital abscess. Surv Ophthalmol 29:169, 1984

Howe L, Jones NS. Guidelines for the management of periorbital cellulitis/abscess. Clin Otolaryngol Allied Sci 2004; 29:725.

Hubert L: Orbital infection due to nasal sinusitis. NY State J Med 37:1559, 1937

Hutcheson KA, Magbalon M. Periocular abscess and cellulitis from Pasteurella multocida in a healthy child. Am J Ophthalmol 1999; 128:514.

Israele V, Nelson JD: Periorbital and orbital cellulitis. Pediatr Infect Dis J 6:404, 1987 
Jacobs D, Galetta S. Diagnosis and management

Jain A, Rubin PAD: Orbital cellulitis in children. Int Ophthalmol Clin 41:71, 2001

Janakarajah N, Sukumaran K: Orbital cellulitis of dental origin: case report and review of the literature. Br J Oral Maxillofac Surg 23:140, 1985

Jarrett WH, Gutman FA: Ocular complications of infection in the paranasal sinuses. Arch Ophthalmol 81:683, 1969

Jarrett WH, Gutman FA: Ocular complications of infection in the paranasal sinuses. Arch Ophthalmol 81:683, 1969

John N Harrington, MD, FACS, Brian A Phillptts, MD, Franisco Talavera, PharmD, PhD, Mark T Duffy, MD, PhD, Lance L Brown, OD, MD. Chief Editor:Hampton Roy Sr, MD, Medscape review version (Preseptal and Orbital cellulitis), Oct 102011.

Jones J, Katz SE, Lubow M. Scedosporium apiospermum of the orbit. Arch Ophthalmol 1999; 117:272.

Karesh J, Lakhanpal V, Haney P, et al: Metastatic anaerobic orbital subperiosteal abscess: value of CT scanning. J Pediatr Ophthalmol Strabismus 19:52, 1982

Karkos PD, Karagama Y, Karkanevatos A, Srinivasan V. Recurrent periorbital cellulitis in a child. A random event or an underlying anatomical abnormality? Int J Pediatr Otorhinolaryngol 2004; 68:1529.

Kaufman SJ: Orbital mucopyoceles: two cases and a review. Surv Ophthalmol 25:253, 1981

Komolafe OO, Ashaye AO. Combined central retinal artery and vein occlusion complicating orbital cellulitis. Niger J Clin Pract 2008; 11:74.

Krohel GB, Kraus HR, Winnick J: Orbital abscesses: presentation, diagnosis, therapy, and sequelae. Ophthalmology 89:492, 1982

Krohel GB, Krauss HR, Christensen RE, Minckler D: Orbital abscess. Arch Ophthalmol 98:274, 1980

Kyprianou I, D'Souza A, Saravanappa N, et al. Referral patterns in paediatric orbital cellulitis. Eur J Emerg Med 2005; 12:6.

Langham-Brown JJ, Rhys-Williams S: Computed tomography of acute orbital infection: the importance of coronal sections. Clin Radiol 40:471, 1989

Lasko B, Lau CY, Saint-Pierre C, et al: Efficacy and safety of oral levofloxacin compared with clarithromycin in the treatment of acute sinusitis in adults: a multicentre, double blind, randomized study. J Int Med Res 26:281, 1998

Lemke BN, Gonnering RS, Harris J, Weinstein JM: Orbital cellulitis with periorbital elevation. Ophthalmic Plast Reconstruct Surg 3:1, 1987

Mair MH, Geley T, Judmaier W, Gassner I. Using orbital sonography to diagnose and monitor treatment of acute swelling of the eyelids in pediatric patients. AJR Am J Roentgenol 2002; 179:1529.

Malik NN, Goh D, McLean C, Huchzermeyer P. Orbital cellulitis caused by Peptostreptococcus. Eye (Lond) 2004; 18:643.

Maniglia AJ, Kronberg FG, Culbertson W: Visual loss associated with orbital and sinus disease. Laryngoscope 94:1050, 1984

Manning SC: Endoscopic management of medial subperiosteal orbital abscess. Arch Otolaryngol Head Neck Surg 119:789, 1993

Mathews D, Mathews JP, Kwartz J, Inkster C. Preseptal cellulitis caused by Acinetobacter lwoffi. Indian J Ophthalmol 2005; 53:213. 
McKinley SH, Yen MT, Miller AM, Yen KG. Microbiology of pediatric orbital cellulitis. Am J Ophthalmol 2007; 144:497.

McLeod SD, Flowers CW, Lopez PF, et al. Endophthalmitis and orbital cellulitis after radial keratotomy. Ophthalmology 1995; 102:1902.

Miller J. Acinetobacter as a causative agent in preseptal cellulitis. Optometry 2005; 76:176.

Mills R. Orbital and periorbital sepsis. J Laryngol Otol 1987; 101:1242.

Mills RP, Kartush JM. Orbital wall thickness and the spread of infection from the paranasal sinuses. Clin Otolaryngol Allied Sci 1985; 10:209.

Milstone AM, Ruff AJ, Yeamans C, Higman MA. Pseudomonas aeruginosa pre-septal cellulitis and bacteremia in a pediatric oncology patient. Pediatr Blood Cancer 2005; 45:353; discussion 354 .

Molarte AB, Isenberg SJ: Periorbital cellulits in infancy. J Pediatr Ophthalmol Strabismus 26:232, 1989

Morell A, Skvaril F, Hitzig WH, Barandum S: IgG subclasses: development of the serum concentrations in "normal" infants and children. J Pediatr 80:960, 1972

Morgan PR, Morrison WV: Complications of frontal and ethmoidal sinusitis. Laryngoscope 90:661, 1980

Nageswaran S, Woods CR, Benjamin DK Jr, et al. Orbital cellulitis in children. Pediatr Infect Dis J 2006; 25:695.

Newell FW, Leveille AS: Management and complications of bacterial periorbital and orbital cellulitis. Metab Pediatr Syst Ophthalmol 6:209, 1982

Noel LP, Clarke WN, Peacocke TA: Periorbital and orbital cellulitis in childhood. Can J Ophthalmol 16:178, 1981Jackson K, Baker SR: Clinical implications of orbital cellulitis. Laryngoscope 96:568, 1986

Okamoto Y, Hiraoka T, Okamoto F, Oshika T. A case of subperiosteal abscess of the orbit with central retinal artery occlusion. Eur J Ophthalmol 2009; 19:288.

Osguthorpe JD, Hochman M. Inflammatory sinus diseases affecting the orbit. Otolaryngol Clin North Am 1993; 26:657.

Partamian LG, Jay WM, Fritz KJ: Anaerobic orbital cellulitis. Ann Ophthalmol 15:123, 1983

Patil B, Agius-Fernandez A, Worstmann T. Hyaluronidase allergy after peribulbar anesthesia with orbital inflammation. J Cataract Refract Surg 2005; 31:1480.

Patt BS, Manning SC. Blindness resulting from orbital complications of sinusitis. Otolaryngol Head Neck Surg 1991; 104:789.

Patt BS, Manning SC: Blindness resulting from orbital complications of sinusitis. Otolaryngol Head Neck Surg 104:789, 1991

Pelton RW, Smith ME, Patel BC, Kelly SM. Cosmetic considerations in surgery for orbital subperiosteal abscess in children: experience with a combined transcaruncular and transnasal endoscopic approach. Arch Otolaryngol Head Neck Surg 2003; 129:652.

Powell KR: Orbital and periorbital cellulitis. Pediatr Rev 16:163, 1995

Quick CA, Payne E: Complicated acute sinusitis. Laryngoscope 82:1248, 1972

R Gentry Wilkerson, MD, Richard H Sinert, DO, Zach Kassutto, MD, FAAP, Elizabeth Fiedler, MD, Edmond A Hooker II, MD, DrPH, FAAEM, Francisco Talavera, PharmD, PhD, Douglas Lavenburg, MD, John D Halamka, MD, MS, Robert E O'Connor, MD, MPH (Chief Editor), eMedicine review (Periorbital infections),jul 10 2011. 
Ragab A, Samaka RM. Department of ORL Head and Neck Surgery, Menoufyia University Hospital, (Is pyogenic ethmoidal osteitis the cause of complicated rhinosinusitis with subperiosteal orbital abscess?).PubMed, Eur Arch Otorhinolaryngol. 2010 Aug;267(8):1231-7. Epub 2010 Jan 13.

Rahbar R, Robson CD, Petersen RA, et al. Management of orbital subperiosteal abscess in children. Arch Otolaryngol Head Neck Surg 2001; 127:281.

Raina UK, Jain S, Monga S, et al. Tubercular preseptal cellulitis in children: a presenting feature of underlying systemic tuberculosis. Ophthalmology 2004; 111:291.

Raja NS, Singh NN. Bilateral orbital cellulitis due to Neisseria gonorrhoeae and Staphylococcus aureus: a previously unreported case. J Med Microbiol 2005; 54:609.

Rees TD, Craig SM, Fisher Y: Orbital abscess following blepharoplasty. Plast Reconstr Surg 73:126, 1983

Reynolds DJ, Kodsi SR, Rubin SE, Rodgers IR. Intracranial infection associated with preseptal and orbital cellulitis in the pediatric patient. J AAPOS 2003; 7:413.

Robbins JB, Schneerson R, Argaman M, Handzel ZT: Haemophilus influenzae type b: disease and immunity in humans. Ann Intern Med 78:259, 1973

Robie F, O'Neal R, Kelsey DS: Periobital cellulitis. J Pediatr Ophthalmol 14:354, 1977

Rubin SE, Rubin LG, Zito J, et al: Medical management of orbital subperiosteal abscess in children. J Pediatr Ophthalmol Strabismus Surg 26:21, 1989

Rubinstein A, Riddell CE. Posterior scleritis mimicking orbital cellulitis. Eye (Lond) 2005; 19:1232.

Rubinstein JB, Handler SD. Orbital and periorbital cellulitis in children. Head Neck Surg 1982; 5:15.

Rubinstein JB, Handler SD: Orbital and periorbital cellulitis in children. Head Neck Surg $5: 15,1982$

Rudloe TF, Harper MB, Prabhu SP, et al. Acute periorbital infections: who needs emergent imaging? Pediatrics 2010; 125:e719.

Rumelt S, Rubin PAD. Potential sources of orbital cellulitis. Int Ophthalmol Clin 36:207, 1996

Russo G, Di Pietro M, La Spina M. Ocular involvement in neuroblastoma: not always metastasis. Lancet Oncol 2004; 5:324.

Ruttum MS, Ogawa G. Adenovirus conjunctivitis mimics preseptal and orbital cellulitis in young children. Pediatr Infect Dis J 1996; 15:266.

Ryan JT, Preciado DA, Bauman N, et al. Management of pediatric orbital cellulitis in patients with radiographic findings of subperiosteal abscess. Otolaryngol Head Neck Surg 2009; 140:907.

Saini JS, Mohan K, Khandalavala B: Wooden foreign bodies of the orbit. Orbit 8:139, 1989

Schmitt NJ, Beatty RL, Kennerdell JS. Superior ophthalmic vein thrombosis in a patient with dacryocystitis-induced orbital cellulitis. Ophthal Plast Reconstr Surg 2005; 21:387.

Schramm VL Jr, Curtin HD, Kennerdell JS. Evaluation of orbital cellulitis and results of treatment. Laryngoscope 1982; 92:732.

Schramm VL, Curtin HD, Kennerdell JS: Evaluation of orbital cellulitis and results of treatment. Laryngoscope 92:732, 1982

Schramm VL, Myers EN, Kennerdell JS: Orbital complications of acute sinusitis: Evaluation, management, and outcome. Trans Am Acad Otolaryngol 86:221, 1978

Schur PH, Rosen F, Norman ME: Immunoglobulin subclasses in normal children. Pediatr Res 13:181, 1979 
Schwartz G. Department of Emergency Medicine, Vanderbilt University Medical Center, (Etiology, Diagnosis, and Treatment of Orbital Infections) - PubMed, Curr Infect Dis Rep. 2002 Jun;4(3):201-205

Scott PM, Bloome MA: Lid necrosis secondary to streptococcal periorbital cellulitis. Ann Ophthalmol 4:461, 1981

Sears JM, Gabriel HM, Veith J. Preseptal cellulitis secondary to Proteus species: a case report and review. J Am Optom Assoc 1999; 70:661.

Shapiro ED, Wald ER, Broznski BA: Periorbital cellulitis and paranasal sinusitis: A reappraisal. Pediatr Infect Dis J 1:91, 1982

Shields CL, Shields JA, Honavar SG, Demirci H. Primary ophthalmic rhabdomyosarcoma in 33 patients. Trans Am Ophthalmol Soc 2001; 99:133.

Shields JA, Shields CL, Suvarnamani C, et al: Retinoblastoma manifesting as orbital cellulitis. Am J Ophthalmol 112:442, 1991

Siber GR, Schur PH, Aisenberg AC, et al: Correlation between serum IgG-2 concentrations and the antibody response to bacterial polysaccharide antigens. $\mathrm{N}$ Engl J Med 303:178, 1980

Silver HS, Fucci MJ, Flanagan JC, Lowry LD: Severe orbital infection as a complication of orbital fracture. Arch Otolaryngol Head Neck Surg 118:845, 1992

Sirbaugh PE. A case of orbital pseudotumor masquerading as orbital cellulitis in a patient with proptosis and fever. Pediatr Emerg Care 1997; 13:337.

Slavin ML, Glaser JS: Acute severe irreversible visual loss with sphenoethmoiditis: 'posterior' orbital cellulitis. Arch Ophthalmol 105:345, 1987

Smith AT, Spencer JT: Orbital complications resulting from lesions of the sinuses. Ann Otol Rhinol Laryngol 57:5, 1948

Smith TF, O'Day D, Wright PF: Clinical implications of preseptal (periorbital) cellulitis in childhood. Pediatrics 62:1006, 1978

Sobol SE, Marchand J, Tewfik TL, et al. Orbital complications of sinusitis in children. J Otolaryngol 2002; 31:131.

Sorin A, April MM, Ward RF. Recurrent periorbital cellulitis: an unusual clinical entity. Otolaryngol Head Neck Surg 2006; 134:153.

Spires JR, Smith RJH: Bacterial infections of the orbital and perirobital soft tissues in children. Laryngoscope 96:763, 1986

Stammberger H: Endoscopic endonasal surgery: concepts in treatment of recurring rhinosinusitis. Otolaryngol Head Neck Surg 94:143, 1986

Stammberger H: Functional Endoscopic Sinus Surgery. p 68. Philadelphia: BC Decker, 1991

Starkey CR, Steele RW. Medical management of orbital cellulitis. Pediatr Infect Dis J 2001; 20:1002.

Swift AC, Charlton G. Sinusitis and the acute orbit in children. J Laryngol Otol 1990; 104:213.

Tannenbaum M, Tenzel J, Byrne SF, et al: Medical management of orbital abscess. Surv Ophthalmol 30:211, 1986

Thatcher DB: Necrotic choroidal melanoma presenting with severe inflammation. Surv Ophthalmol 12:247, 1967

Towbin R, Han BK, Kaufman RA, Burke M: Postseptal cellulitis: CT in diagnosis and management. Radiology 158:735, 1986

Uehara F, Ohba N: Diagnostic imaging in patients with orbital cellulitis and inflammatory pseudotumor. Int Ophthalmol Clin 42:133, 2002 
Uzcátegui N, Warman R, Smith A, Howard CW. Clinical practice guidelines for the management of orbital cellulitis. J Pediatr Ophthalmol Strabismus 1998; 35:73.

Uzcategui N, Warman R, Smith A, Howard CW: Clinical practice guidelines for the management of orbital cellulitis. J Pediatr Ophthalmol Strabismus 35:73, 1998

Vail DT: Orbital complications in sinus disease: a review. Am J Ophthalmol 14:202, 1931

Varma D, Metcalfe TW. Orbital cellulitis after peribulbar anaesthesia for cataract surgery. Eye (Lond) 2003; 17:105.

Velazquez AJ, Goldstein MH, Driebe WT. Preseptal cellulitis caused by trichophyton (ringworm). Cornea 2002; 21:312.

von Noorden GK: Orbital cellulitis following extraocular muscle surgery. Am J Ophthalmol 74:627, 1972

Watters EC, Wallar H, Hiles DA, Michaels RH: Acute orbital cellulitis. Arch Ophthalmol 94:785, 1976

Weakley DR. Orbital cellulitis complicating strabismus surgery: a case report and review of the literature. Ann Ophthalmol 1991; 23:454.

Weber AL, Mikulis DK. Inflammatory disorders of the paraorbital sinuses and their complications. Radiol Clin North Am 1987; 25:615.

Weiss A, Friendly D, Eglin K, et al: Bacterial periorbital and orbital cellulitis in childhood. Ophthalmology 90:195, 1983

Welsh LW, Welsh JJ: Orbital complications of sinus disease. Laryngoscope 84:848, 1974

Westfall CT, Shore JW: Isolated fractures of the orbital floor: risk of infection and the role of the antibiotic prophylaxis. Ophthalmic Surg 22:409, 1991

Whitnall SE: The Anatomy of the Human Orbit and Accessory Organ of Vision. 2nd ed, pp 29-35.New York: Oxford University Press, 1932

Williamson-Nobel FA: Diseases of the orbit and its contents secondary to pathological conditions of the nose and paranasal sinuses. Ann R Coll Surg 15:46, 1954

Wilson ME, Paul TO: Orbital cellulitis following strabismus surgery. Ophthalmic Surg 18:92, 1987

Wulc AE, Adams JL, Dryden RM: Cerebrospinal fluid leakage complicating orbital exenteration. Arch Ophthalmol 107:827, 1989

Wulc, AC. Orbital infections. In: Duane's Ophthalmology 1999 CD ROM edition, Volume 2, Chapter 34.Williams BJ, Harrison HC: Subperiosteal abscesses of the orbit due to sinusitis in childhood. Aust NZ J Ophthalmol 19:29, 1991

Younis RT, Lazar RH, Bustillo A, Anand VK. Department of Otolaryngology, University of Miami School of Medicine, (Orbital infection as a complication of sinusitis: are diagnostic and treatment trends changing?) PubMed, Ear Nose Throat J. 2002 Nov;81(11):771-5.

Younis RT, Lazar RH, Bustillo A, Anand VK: Orbital infection as a complication of sinusitis: are diagnostic and treatment trends changing. Ear, Nose, Throat J 81:771, 2002

Youssef Z, Pennefather PM, Watts MT. Orbital cellulitis vs allergic reaction to hyaluronidase as the cause of periorbital oedema. Eye (Lond) 2005; 19:691.

Zhanel GG, Ennis K, Vercaine L, et al: A critical review of the fluoroquinolones. Drugs 62:13, 2002

Ziakas NG, Boboridis K, Gratsonidis A, et al. Wegener's granulomatosis of the orbit in a 5year-old child. Eye (Lond) 2004; 18:658.

Zimmerman RA, Bilaniuk LT: CT of orbital infection and its cerebral complications. AJR 134:45, 198 
(C) 2012 The Author(s). Licensee IntechOpen. This is an open access article distributed under the terms of the Creative Commons Attribution 3.0 License, which permits unrestricted use, distribution, and reproduction in any medium, provided the original work is properly cited. 